\title{
PENENTUAN CADANGAN PREMI DENGAN METODE PREMIUM SUFFICIENCY PADA ASURANSI JIWA SEUMUR HIDUP JOINT LIFE
}

\author{
Ni Putu Mirah Permatasari ${ }^{1 \S}$, I Nyoman Widana ${ }^{2}$ Kartika Sari $^{3}$ \\ ${ }^{1}$ Jurusan Matematika, Fakultas MIPA - Universitas Udayana [Email: mirahpermataa@ gmail.com] \\ ${ }^{2}$ Jurusan Matematika, Fakultas MIPA - Universitas Udayana [Email: nwidana@yahoo.com] \\ ${ }^{3}$ Jurusan Matematika, Fakultas MIPA - Universitas Udayana [Email: sari_kaartika@yahoo.co.id] \\ ${ }^{\S}$ Corresponding Author
}

\begin{abstract}
The aim of this research was to get the formula of premium reserves through the premium sufficiency method. Premium reserve is the amount of fund that is collected by the insurance company in preparation for the claim's payment. Premium sufficiency method is gross premium calculation. To construct that formula, this research used Tabel Mortalitas Indonesia (TMI) 2011, interest rate 2.5\% and cost of alpha $0.05 \%$. Based on simulation result in men premium reserve value of age 1 of 56 years propotional with insured periods, but after56 years enhancement of premium reserve value.
\end{abstract}

Keywords: Joint Life Insurance, Premium Reserve, Premium Sufficiency

\section{PENDAHULUAN}

Asuransi jiwa seumur hidup adalah asuransi yang memberikan perlindungan mulai dari awal disepakatinya kontrak sampai meninggal dunia (Sembiring, 1986). Berdasarkan banyaknya tertanggung asuransi jiwa dibedakan menjadi 2, yaitu asuransi jiwa tunggal dan asuransi jiwa kumpulan. Asuransi jiwa Joint Life adalah asuransi jiwa yang menanggung 2 orang pemegang polis atau lebih (Futami [2]).

Salah satu metode perhitungan cadangan premi dengan perhitungan premi kotor adalah metode premium sufficiency. Premi kotor dihitung dengan melibatkan biaya yang diperlukan perusahaan (Futami, 1994).

Pada penelitian sebelumnya siregar (2014), telah melakukan perhitungan cadangan premi asuransi dwiguna joint life status last survivor dengan metode premium sufficienc. Sementara itu, sejauh ini peneliti belum menemukan penelitian mengenai perhitungan cadangan premi dengan metode premium sufficiency pada asuransi jiwa seumur hidup joint life. Oleh karena itu dalam penelitian ini dibahas perhitungan cadangan premi dengan metode premium sufficiency pada asuransi jiwa seumur hidup joint life.

Selanjutnya dibahas konsep-konsep yang digunakan untuk menentukan formula cadangan premi.

Anuitas hidup adalah suatu anuitas yang pembayarannya dilakukan selama tertanggung masih hidup (Futami, 1993). Nilai sekarang anuitas awal dari anuitas seumur hidup untuk pemegang polis berusia $x$ tahun dengan uang pertanggungan sebesar $R p .1$, - dirumuskan sebagai (Futami, 1993):

$$
\begin{aligned}
\ddot{a}_{x}= & 1+v p_{x}+v^{2}{ }_{2} p_{x}+\cdots+ \\
& v^{\omega-x-1}{ }_{\omega-x-1} p_{x}
\end{aligned}
$$

Persamaan (1) dapat digeneralisasikan untuk merumuskan nilai sekarang anuitas awal dari anuitas seumur hidup joint life pada pemegang polis berusia $x$ tahun dan $y$ tahun dengan uang pertanggungan sebesar $R p .1$, - menjadi:

$$
\begin{array}{r}
\ddot{a}_{x y}=1+v p_{x y}+v^{2}{ }_{2} p_{x y}+\cdots \\
+v^{\omega-x, \omega-y}{ }_{\omega-x-1, \omega-y-1} p_{x y}
\end{array}
$$




$$
\text { Karena } \quad p_{x y}=\frac{l_{x+1, y+1}}{l_{x y}} \quad, \quad \text { maka }
$$
persamaan (2) dapat ditulis sebagai:

$$
\begin{gathered}
\ddot{a}_{x y}=1+v \frac{l_{x+1, y+1}}{l_{x y}}+v^{2} 99 \frac{l_{x+2, y+2}}{l_{x y}}+\cdots \\
\quad+ \\
v^{\omega-x-1, \omega-y-1} \frac{l_{\omega, \omega}}{l_{x y}}
\end{gathered}
$$

Persamaan (3) dikalikan dengan $\left(\frac{v^{\frac{1}{2}(x+y)}}{v^{\frac{1}{2}(x+y)}}\right)$, diperoleh:

$$
\begin{aligned}
\ddot{a}_{x y}= & \\
\frac{1}{v^{\frac{1}{2}(x+y)}} l_{x y} & \left(v^{\frac{1}{2}(x+y)} l_{x y}+\right. \\
& v^{\frac{1}{2}(x+y+2)} l_{x+1, y+1}+ \\
& v^{\frac{1}{2}(x+y+4)} l_{x+2, y+2}+\cdots+ \\
& \left.v^{\omega-x, \omega-y} l_{\omega, \omega}\right)
\end{aligned}
$$

Selanjutnya karena $D_{x y}=v^{\frac{1}{2}(x+y)} \times l_{x y}$, maka persamaan (4) menjadi:

$$
\begin{aligned}
\ddot{a}_{x y}= & \frac{1}{D_{x y}}\left(D_{x y}+D_{x+1, y+1}+D_{x+2, y+2}+\right. \\
& \left.\cdots+D_{\omega, \omega}\right)
\end{aligned}
$$

Karena $N_{x y}=D_{x y}+D_{x+1, y+1}+D_{x+2, y+2}+$ $\cdots+D_{\omega, \omega}$, maka persamaan (5) menjadi:

$$
\ddot{a}_{x y}=\frac{N_{x y}}{D_{x y}}
$$

Sedangkan untuk pemegang polis berusia $x+t$ tahun dan $y+t$ tahun maka persamaan (6) menjadi:

$$
\ddot{a}_{x+t, y+t}=\frac{N_{x+t, y+t}}{D_{x+t, y+t}}
$$

Premi adalah sejumlah uang yang wajib dibayarkan oleh tertanggung kepada perusahaan sesuai dengan kontrak yang telah disepakati. Premi yang dibayarkan sekaligus disebut premi tunggal sedangkan premi yang dibayar berkala setiap tahun disebut premi tahunan (Futami, 1993

Perhitungan premi tunggal asuransi jiwa seumur hidup untuk pemegang polis berusia $x$ tahun dinotasikan $A_{x}$ dan dirumuskan sebagai (Futami, 1993):

$$
\begin{gathered}
A_{x}=v \frac{l_{x}-l_{x+1}}{l_{x}}+v^{2} \frac{l_{x+1}-l_{x+2}}{l_{x}}+\cdots+ \\
v^{\omega-x} \frac{l_{\omega-x-1}}{l_{x}}
\end{gathered}
$$

Persamaan (8) dapat digeneralisasikan untuk merumuskan premi tunggal asuransi jiwa seumur hidup joint life pada pemegang polis berusia $x$ tahun dan $y$ tahun dengan uang pertanggungan sebesar $R p .1$, - diperoleh:

$$
\begin{aligned}
A_{x y}=v \frac{l_{x y}-}{l_{x+1, y+1}} & l_{x y} \\
& +v^{2} \frac{l_{x+1, y+1}-l_{x+2, y+2}}{l_{x y}} \\
& +\cdots+v^{\omega-x-1, \omega-y-1} \frac{l_{\omega, \omega}}{l_{x y}}
\end{aligned}
$$

Persamaan (9) dikalikan dengan $\left(\frac{v^{\frac{1}{2}(x+y)}}{v^{\frac{1}{2}(x+y)}}\right)$, menjadi

$$
\begin{aligned}
A_{x y}= & \frac{1}{v^{\frac{1}{2}(x+y)} l_{x y}}\left(v ^ { \frac { 1 } { 2 } ( x + y ) + 1 } \left(l_{x y}-\right.\right. \\
& \left.l_{x+1, y+1}\right)+v^{\frac{1}{2}(x+y)+2}\left(l_{x+1, y+1}-\right. \\
& \left.\left.l_{x+2, y+2}\right)+\cdots+v^{\omega-x, \omega-y} l_{\omega, \omega}\right)
\end{aligned}
$$

Karena $\quad C_{x y}=v^{\frac{1}{2}(x+y)+1} \times d_{x y} \quad, \quad$ maka persamaan (10) menjadi:

$$
\begin{aligned}
A_{x y}= & \frac{1}{D_{x, y}}\left(C_{x, y}+C_{x+1, y+1}+C_{x+2, y+2}+\right. \\
& \left.\cdots+C_{\omega, \omega}\right)
\end{aligned}
$$

Selanjutnya karena $M_{x y}=C_{x y}+C_{x+1, y+1}+$ $C_{x+2, y+2}+\cdots+C_{\omega, \omega}$, maka persamaan (11) dapat ditulis sebagai:

$$
A_{x y}=\frac{M_{x y}}{D_{x y}}
$$

Sama halnya dengan nilai anuitas hidup, untuk pemegang polis berusia $x+t$ dan pemegang polis berusia $y+t$ persamaan (12) menjadi:

$$
A_{x+t, y+t}=\frac{M_{x+t, y+t}}{D_{x+t, y+t}}
$$

Premi tahunan asuransi jiwa seumur hidup untuk pemegang polis berusia $x$ tahun yang 
dibayarkan pada awal tahun dinotasikan dengan $P_{x}$ dan dirumuskan sebagai

$$
P_{x}=\frac{A_{x}}{\ddot{a}_{x}}
$$

Persamaan (14) dapat digeneralisasikan untuk merumuskan premi tahunan asuransi jiwa seumur hidup joint life bagi pemegang polis berusia $x$ tahun dan $y$ tahun untuk uang pertanggungan sebesar $R p .1,-$ dibayarkan di akhir tahun menjadi:

$$
P_{x y}=\frac{A_{x y}}{\ddot{a}_{x y}}
$$

Selanjutnya, berdasarkan persamaan (6) dan persamaan (12), maka persamaan (15) menjadi:

$$
P_{x y}=\frac{M_{x y}}{N_{x y}}
$$

\section{METODE PENELITIAN}

Pada penelitian ini data yang digunakan adalah data sekunder yang bersumber dari artikel sebagai hasil penelitian siregar (2014).

Langkah yang dilakukan adalah menghitung nilai dari tabel mortalitas joint life berdasarkan Tabel Mortalitas Indonesia (TMI) 2011, selanjutnya menghitung nilai dari tabel komutasi joint life dengan tingkat bunga 2,5\%, lebih lanjut lagi dapat dilakukan perhitungan cadangan premi dengan metode premium sufficiency melalui simulasi dari peserta asuransi jiwa seumur hidup joint life.

Untuk memudahkan perhitungan, dalam penelitian ini digunakan program Software Microsoft Excel

\section{HASIL DAN PEMBAHASAN}

Sebelum memperoleh formula cadangan premi pada asuransi jiwa seumur hidup joint life maka terlebih dahulu ditentukan premi kotor pada asuransi jiwa seumur hidup joint life. Formula Premi Kotor pada Asuransi JIwa Seumur Hidup Joint Life diperoleh:

$$
P_{x y}^{*}=\frac{1}{1-\beta}\left\{P_{x y}+\frac{\alpha}{\ddot{a}_{x y}}+\gamma\right\}
$$

Karena berlaku persamaan (6) dan persamaan (16) maka persamaan (17) dapat ditulis sebagai:

$$
P_{x y}^{*}=\frac{1}{1-\beta}\left\{\frac{M_{x y}}{D_{x y}}+\frac{\alpha D_{x y}}{N_{x y}}+\gamma\right\}
$$

Selanjutnya formula cadangan premi dengan metode Premium Sufficiency pada asuransi jiwa seumur hidup Joint Life diperoleh:

$$
\begin{gathered}
{ }_{t} V_{x y}=A_{x+t, y+t}-\left(P_{x y} a_{x+t, y+t}+\right. \\
\left.\frac{\alpha}{a_{x y}}\right) a_{x+t, y+t}
\end{gathered}
$$

Karena berlaku persamaan (7), (13) dan (16) maka persamaan (19) menjadi:

$$
{ }_{t} V_{x y}=\frac{1}{D_{x+t, y+t}}\left(M_{x+t, y+t}-\left(M_{x y}+\alpha D_{x y}\right) \frac{N_{x+t, y+t}}{N_{x y}}\right)(22)
$$

\section{SIMULASI}

Terdapat dua orang pemegang polis yang mengikuti asuransi jiwa seumur hidup joint life pada salah satu perusahaan asuransi jiwa. Usia pemegang polis mulai mengikuti asuransi jiwa adalah usia $(x)=35$ tahun dan $(y)=30$ tahun. Pembayaran premi dilakukan setiap tahun selama pemegang polis masih hidup. Uang pertanggungan sebesar Rp,10.000.000,-. Asuransi jiwa berakhir jika pemegang polis berusia $x$ tahun atau $y$ tahun meninggal dunia.

Berdasarkan Tabel 4.1 dapat dilihat apabila salah satu dari pemegang polis berusia $x=35$ dan pemegang polis berusia $y=30$ tahun meninggal 1 tahun kemudian maka nilai cadangan premi pada asuransi jiwa seumur hidup joint life adalah Rp.110313.07683, selanjutnya setelah 2 tahun nilai cadangan preminya adalah $R p .273801 .78611$ dan demikian seterusnya.

Selanjutnya, jika dibuat grafik hubungan antara nilai cadangan premi dengan peningkatan tahunya berikut dapat dilihat grafik seperti pada gambar 1. 
Tabel 4.1 Nilai Cadangan Premi dengan Metode Premium Sufficiency pada Asuransi Jiwa Seumur Hidup Joint Life untuk pemegang polis berusia $x=35$ dan berusia $y=30$

\begin{tabular}{|c|c|c|c|}
\hline $\begin{array}{l}\text { Jangka } \\
\text { Waktu } \\
(t)\end{array}$ & ${ }_{t} V(R p)$ & $\begin{array}{l}\text { Jangka } \\
\text { Waktu } \\
(t)\end{array}$ & ${ }_{t} V(R p)$ \\
\hline 1 & 110313.077 & 39 & 6912912.050 \\
\hline 2 & 273801.786 & 40 & 7069925.861 \\
\hline 3 & 440395.614 & 41 & 7223596.827 \\
\hline 4 & 610221.357 & 42 & 7373892.167 \\
\hline 5 & 783041.369 & 43 & 7520010.182 \\
\hline 6 & 958633.930 & 44 & 7661075.859 \\
\hline 7 & 1136439.253 & 45 & 7796204.888 \\
\hline 8 & 1316448.851 & 46 & 7925524.377 \\
\hline 9 & 1498751.755 & 47 & 8048302.702 \\
\hline 10 & 1683030.698 & 48 & 8165640.620 \\
\hline 11 & 1869076.058 & 49 & 8278009.997 \\
\hline 12 & 2056463.750 & 50 & 8385413.361 \\
\hline 13 & 2244726.723 & 51 & 8487491.066 \\
\hline 14 & 2433512.339 & 52 & 8582241.210 \\
\hline 15 & 2622651.547 & 53 & 8669300.067 \\
\hline 16 & 2811643.855 & 54 & 8749207.294 \\
\hline 17 & 2999894.468 & 55 & 8822046.964 \\
\hline 18 & 3186997.953 & 56 & 8887723.504 \\
\hline 19 & 3372994.306 & 57 & 8950377.397 \\
\hline 20 & 3557948.972 & 58 & 9007644.887 \\
\hline 21 & 3741955.145 & 59 & 9059546.376 \\
\hline 22 & 3925073.372 & 60 & 9105350.379 \\
\hline 23 & 4107219.367 & 61 & 9145277.128 \\
\hline 24 & 4288409.864 & 62 & 9187062.764 \\
\hline 25 & 4468813.378 & 63 & 9228862.006 \\
\hline 26 & 4648579.511 & 64 & 9268968.912 \\
\hline 27 & 4827950.663 & 65 & 9305747.216 \\
\hline 28 & 5007109.043 & 66 & 9335079.000 \\
\hline 29 & 5186142.108 & 67 & 9360645.234 \\
\hline 30 & 5364872.609 & 68 & 9379281.401 \\
\hline 31 & 5543029.516 & 69 & 9400886.154 \\
\hline 32 & 5720447.231 & 70 & 9423381.729 \\
\hline 33 & 5897192.740 & 71 & 9444757.346 \\
\hline 34 & 6072200.435 & 72 & 9465328.422 \\
\hline 35 & 6246007.313 & 73 & 9486105.975 \\
\hline 36 & 6417804.370 & 74 & 9512996.958 \\
\hline 37 & 6587333.684 & 75 & 9584489.499 \\
\hline 38 & 6752183.723 & 76 & 0 \\
\hline
\end{tabular}

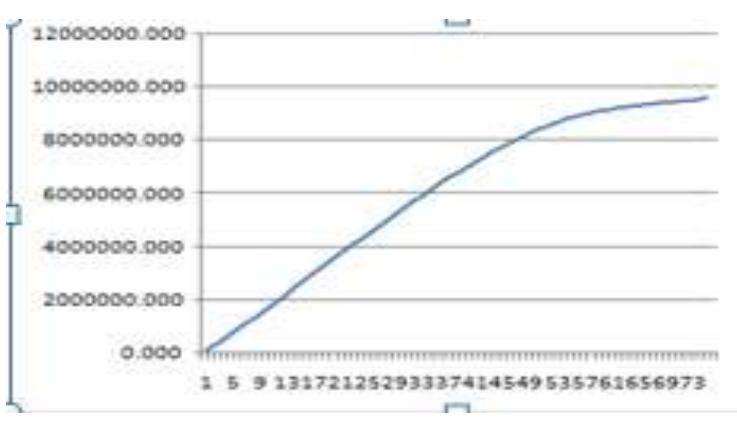

Gambar 1. Plot Hubungan antara Peningkatan Nilai Cadangan Premi dengan Periode Asuransi Jiwa.

Berdasarkan gambar 1, peningkatan nilai cadangan premi dari tahun ke 1 sampai tahun ke 56 proposional dengan peningkatan tahun, akan tetapi setelah tahun ke 56 peningkatan nilai cadangan premi mulai lambat.

\section{KESIMPULAN}

Penelitian ini bertujuan untuk mendapatkan formula cadangan premi pada asuransi jiwa seumur hidup joint life. Metode yang digunakan untuk menentukan formula tersebut adalah metode premium sufficiency, yaitu metode perhitungan premi kotor. Pada penelitian ini menggunakan Tabel Mortalitas Indonesia (TMI) 2011, tingkat suku bunga sebesar 2,5\% dan biaya alpha $(\alpha)=0.05 \%$. Hasil penelitian ini adalah berupa formula cadangan premi untuk asuransi jiwa seumur hidup joint life bagi pemegang polis berusia $x$ tahun dan $y$ tahun. Berdasarkan hasil simulasi, dapat dilihat pada grafik 1, peningkatan nilai cadangan premi dari tahun ke 1 sampai tahun ke 56 proposional dengan peningkatan tahun, akan tetapi setelah tahun ke 56 peningkatan nilai cadangan premi mulai lambat. 


\section{DAFTAR PUSTAKA}

Futami, T., 1993. Matematika Asuransi Jiwa Bagian I. Herliyanto G, penerjemah. Tokyo (JP): Oriental Life Insurance Cultural Development Center. Terjemahan dari: Seime Hoken Sugaku Gekan ("92 Revision).

,1994. Matematika Asuransi Jiwa Bagian 2. Herliyanto G, penerjemah. Tokyo (JP): Oriental Life Insurance Cultural Development Center. Terjemahan dari: Seime Hoken Sugaku Gekan ("92 Revision).

Siregar, M. T. 2014. Cadangan Asuransi Dwiguna Last Survivor dengan Metode Premium Sufficiency. JOM FMIPA , 447456.

Sembiring, R.K., 1986. Buku Materi PokokAsuransi I. Jakarta: Universitas Terbuka, Depdikbud.

Biro Pusat Aktuaria (Independent and Trusted).,2012.Tabel Mortalita Taspen 2012. Jakarta: PT.Taspen, https://ml.scribd.com/doc/211956752/TMT2012, diakses tanggal 20 Juli 2015. 